\title{
AN ENDOGENOUS SWITCHING SIMULTANEOUS EQUATION SYSTEM OF EMPLOYMENT, INCOME AND CAR OWNERSHIP
}

\author{
Chandra R. Bhat \\ Research Assistant Professor \\ Transportation Center \\ Northwestern University \\ Evanston, Illinois 60208 \\ and \\ Frank S. Koppelman \\ Professor of Civil Engineering \\ and Transportation \\ Northwestern University \\ Evanston, Illinois 60208
}

\begin{abstract}
The research presented here makes an advance toward the inclusion of employment and income within a transportation framework based on the conceptual framework developed by the authors in a preceding paper. Employment and income are important determinants of travel behavior. They have been used as exogenous variables in travel forecasting models such as trip generation models, car ownership models, and mode choice models. This paper proposes a fundamental change in the current view of employment and income as exogenous variables in travel demand models. In particular, we emphasize the need, both from a forecasting and estimation point of view, to include employment and income as endogenous variables within a disaggregate travel demand modeling framework. The paper formulates and estimates an integrated model of employment, income and car ownership which takes account of interdependencies among these variables and their structural relationships with relevant exogenous variables.
\end{abstract}




\section{Introduction}

Traditional trip-based travel analyses consider the number of workers in a household and household income as exogenous variables. Data on employment and income is obtained from supplementary demographic forecasts. Such supplementary demographic forecasts are, in general, of an aggregate nature and do not support reliable disaggregate travel behavior analysis. This paper argues for the consideration of employment and income within a disaggregate travel demand framework and formulates and estimates a joint model system of employment, income and car ownership.

The next section discusses the methodological need to model employment and income within a transportation context. The third section discusses the data source used for empirical analysis and discusses the sample used for the analysis. The fourth section advances a structure for the integrated model system and presents the estimation methodology. The fifth section presents the empirical specification and results of the model system. A brief summary and conclusions are presented in the final section.

\section{Need to Model Employment and Income within Travel Demand Framework}

In an earlier paper, we emphasized the need to model employment and income from an activitybased perspective to travel demand modeling (Bhat and Koppelman, 1993). Here we argue that the need (to model employment and income) is also important from a trip-based approach to travel demand modeling.

The number of workers in a household and household income are very important variables in travel demand models such as car ownership models (Golob, 1989; Kitamura 1988), trip generation models (Meurs, 1989), and mode choice models (Beggan, 1988). Despite their fundamental importance as determinants of travel behavior, the forecasting of employment and income has been treated outside the framework of the transportation planning cycle. Employment and income forecasts are relegated to simple aggregate-level side-calculations rather than being based on causal models that address the behavioral factors underlying employment decisions and income-earning potential. Such aggregate-level forecasts fail to adequately represent the distribution of changes in employment and income across various socio-demographic groups. This is likely to lead to inconsistent employment and income forecasts and, consequently, misleading and inaccurate forecasting of travel-related variables. A causal disaggregate model of employment and income, 
using readily available transportation planning data, can be used as part of an overall transportation planning process and will support reliable travel behavior analysis. ${ }^{1}$

In addition to the need to obtain reliable forecasts of employment and income, consideration of employment and income within a travel framework is also important for consistent parameter estimation of travel demand models. There are two sources of potential inconsistency in traditional estimation procedures. The first arises because traditional methods ignore the correlation in unobserved factors that may affect the employment decision of individuals in a household and the travel related variable under consideration (car ownership in this paper). The second source of inconsistency arises from the manner in which traditional methods treat grouped (or interval-level) income data. Traditional procedures handle grouped income data by using midpoints of class intervals. Open-ended groups (i.e., the two groups at either extreme of the income spectrum) are assigned values on an even more ad hoc basis. Such a method will, in general, not result in consistent parameter estimates of travel demand models (Hsiao, 1983). ${ }^{2}$

We use an endogenous switching equation system of employment, income and car ownership to overcome the two sources of inconsistencies discussed above.

\section{Data Source and Sample Formation}

The data source used in the present study is the Dutch National Mobility Panel (Van Wissen and Meurs, 1989). This panel was instituted in 1984, and involves weekly travel diaries and household and personal questionnaires collected at biannual and annual intervals. Ten waves (a wave refers to cross-sectional data at one time point) were collected between March, 1984 and March, 1989. Data for our analysis is obtained from waves 1,3,5,7 and 9 of the panel collected during the spring of each year between (and including) 1984 and 1988. The data was screened to include only nuclear family households ${ }^{3}$ in which the husband is employed. We removed households in which the husband was unemployed because there were too few of them to undertake any meaningful analysis of the husband's employment. Households in which adults are self-employed were excluded because the

\footnotetext{
${ }^{1}$ The introduction of car ownership as a component of the demand forecasting cycle emerged about two decades ago from a similar need for a disaggregate causal modeling of car ownership (Lerman and Ben-Akiva 1975). Today, car ownership modeling is considered an integral part of the disaggregate forecasting process.

${ }^{2}$ See also Gaudry (1979) for a discussion of the importance of the joint treatment of work-related variables and travel demand variables from an equilibrium-oriented demand framework.

${ }^{3}$ A nuclear family household comprises two adults, a male and a female, with one or more children below the age of 18 .
} 
concept of income is not clearly defined for such individuals. Households with seniors over 60 years and/or disabled persons were removed from the sample due to their low rate of employment. The resulting sample includes 2279 observations of nuclear family households. We do not account in this paper for biases in the standard errors due to repeated measurements on households which occur in more than one wave.

\section{Model System}

The endogenous variables in our model are husband's income, wife's employment choice, wife's income and household car ownership. In this section, we develop the equation system of the model and also present the econometric procedure used in estimation. We use a limited information maximum likelihood procedure to estimate the system. In this limited information procedure, each equation is estimated individually after appropriately accounting for the limited dependent nature of the endogenous variable. The income variables occurring on the right hand side of other equations are replaced by their imputed values obtained from the estimation of their respective equations (these imputed income values are unbiased estimators of the actual income values). In the following presentation, the subscript $i$ denotes observations (or households) and all references to income are in real value terms.

\subsection{Husband's Income}

The first equation in the model system is husband's income. We use a logarithm transformation of income, and express this transformed variable as a linear function of independent variables (an extensive treatment of the theoretical appropriateness of a log-normal form for the income distribution is available in Aitchison and Brown, 1976, and Mincer, 1974). The grouped nature of income is addressed by defining a continuous index function (also referred to as a latent function) for the logarithm of husband's income, $I_{h i}^{*}$. We do not observe $I_{h i}^{*}$ but observe that $I_{h i}^{*}$ falls into a certain interval. The first equation of our system is then written as:

$$
\begin{aligned}
& I_{h i}^{*}=\pi_{h}^{\prime} \omega_{h i}+v_{h i} \\
& I_{h i}=j, \text { if } \frac{a_{j-1}}{p_{i}}<I_{h i}^{*} \leq \frac{a_{j}}{p_{i}}, j=1,2, \ldots, J
\end{aligned}
$$


where $v_{h i}$ is a normal random error term with mean 0 and variance $\sigma_{h}, \omega_{h i}$ is a vector of exogenous variables affecting husband's (log) income and $\pi_{h}$ is a corresponding vector of parameters. The $a_{j}$ 's in the equation represent known threshold values for each income category $j$. These thresholds are normalized by the price index $p_{i}$ to obtain the equivalent real-income censoring bounds. Since the price index $p_{i}$ varies among observations, the thresholds are not fixed. The $J$ income intervals exhaust the real line and hence we assume $a_{0} / p_{i}=-\infty$ and $a_{J} / p_{i}=+\infty$. Representing the cumulative standard normal by $\Phi$, the probability that husband's income falls in category $j$ may be written

$$
\operatorname{prob}\left(I_{h i}=j\right)=\Phi\left(\frac{A_{j, i}-\pi_{h}^{\prime} \omega_{h i}}{\sigma_{h}}\right)-\Phi\left(\frac{A_{j-1, i}-\pi_{h}^{\prime} \omega_{h i}}{\sigma_{h}}\right) .
$$

Defining a set of dummy variables

$$
M_{i j}=\left\{\begin{array}{l}
1 \text { if } I_{m i} \text { falls in the } j \text { th category } \\
0 \text { otherwise, }
\end{array}(i=1,2, \ldots N, j=1,2, \ldots J),\right.
$$

the likelihood function for estimation of the parameters $\pi_{h}$ and $\sigma_{h}$ is

$$
L_{h}=\prod_{i=1}^{N} \prod_{j=1}^{J}\left[\Phi\left(\frac{A_{j, i}-\pi_{h}^{\prime} \omega_{h i}}{\sigma_{h}}\right)-\Phi\left(\frac{A_{j-1, i}-\pi_{h}^{\prime} \omega_{h i}}{\sigma_{h}}\right)\right]^{M_{i j}}
$$

Initial start values for maximum likelihood (ML) iterations are obtained by assigning to each income observation its conditional expectation based on the marginal distribution of $I_{h i}^{*}$ and then regressing these conditional expectations on the vector of exogenous variables. ${ }^{4}$

An imputed value for husband's (log) income is computed from the estimation of equation (4) as $\hat{I}_{h i}=\hat{\pi}_{h}^{\prime} \omega_{h}$ and is used for husband's (log) income in subsequent equations.

\footnotetext{
${ }^{4}$ In a recent paper, Stern (1991) maximizes equation (4) using a two-step procedure rather than a direct maximization procedure. The two-step procedure is not only inefficient, but also is tedious compared to the direct and computationally simple maximization procedure used here. His procedure also does not provide an estimate of $\sigma_{\mathrm{h}}$ and assumes that the thresholds (the $A_{j, i}$ 's in equation 4) are fixed across all observations.
} 


\subsection{Wife's Employment}

The second equation in our model system is the wife's employment decision. Wife's employment choice is a function of exogenous variables and household assets or unearned income. In our model, husband's (log) income is treated as unearned income to the wife; that is, the wife regards her husband as an "income producing asset" which affects her work decision (Cogan 1980).

We define a latent continuous function $E_{i}^{*}$ denoting the wife's employment propensity and view the discrete employment decision $E_{i}$ as a reflection of this underlying propensity. If this propensity exceeds zero, the wife will work. Otherwise, she will not work. We may write the relationship between the latent employment propensity and the discrete employment decision in equation form as follows:

$$
\begin{aligned}
& E_{i}^{*}=\pi_{e}^{\prime} \omega_{e i}+\gamma_{e} \hat{I}_{h i}+v_{e i} \\
& E_{i}=1 \text { if } E_{i}^{*}>0 \\
& E_{i}=0 \text { if } E_{i}^{*} \leq 0
\end{aligned}
$$

where the vector $\omega_{e i}$ represents a vector of exogenous variables affecting wife's employment. We assume a normal distribution for the random error term $v_{e i}$ with mean zero and unit variance. This will be recognized as the familiar probit model. The parameters $\pi_{e}$ and $\gamma_{e}$ are estimated using a univariate probit procedure.

\subsection{Wife's Income}

Wife's income is conditional on her employment status. In addition, it is available only in grouped form. We specify an index function of wife's income and assume a lognormal distribution for this function. Defining the index function for wife's $(\log )$ income as $I_{w i}{ }^{*}$ and the observed categorical wife's income data as $I_{w i}$, we write

$$
\left.\begin{array}{c}
I_{w i}^{*}=\pi_{w}^{\prime} \omega_{w i}+\gamma_{w} \hat{I}_{h i}+v_{w i} \\
I_{w i}=l, \text { if } \frac{d_{l-1}}{p_{i}}<I_{w i}^{*} \leq \frac{d_{l}}{p_{i}}
\end{array}\right\} \text { observed only if } E_{i}^{*}>0,
$$


where $l$ is an index for categories $(l=1,2, \ldots L), d_{l}$ represents the thresholds of absolute income and $p_{i}$ is the price index. The variable vector $\omega_{w}$ contains exogenous variables affecting wife's income and $v_{w i}$ is a normal random error term with mean 0 and variance $\sigma_{w}{ }^{5}$

Wife's income (in log form) is a censored grouped variable (the censoring based on employment). Limiting our attention to observations in the uncensored portion and estimating parameters by a grouped data method similar to the one employed for husband's income equation is subject to problems of selection bias (Heckman, 1979; Greene, 1983). Assuming a bivariate normal distribution between the conditional distributions of the underlying latent wife's employment and income functions, and defining

$$
\tilde{\pi}_{e}=\left(\pi_{e}^{\prime}, \gamma_{e}\right)^{\prime}, \widetilde{\pi}_{w}=\left(\pi_{w}^{\prime}, \gamma_{w}\right)^{\prime}, \widetilde{\omega}_{e i}=\left(\omega_{e i}^{\prime}, \hat{I}_{h i}^{*}\right)^{\prime}, \text { and } \widetilde{\omega}_{w i}=\left(\omega_{w i}^{\prime}, \hat{I}_{h i}^{*}\right)^{\prime}
$$

the appropriate maximum likelihood estimation (MLE) procedure for estimation of the parameters is shown in the following equation: ${ }^{6}$

$$
\begin{aligned}
L_{f} & =\prod_{i=1}^{N}\left[1-\Phi\left(\tilde{\pi}_{e}^{\prime}{ }_{e} \varpi_{e i}\right)\right]^{1-E_{i}} \\
& \times\left[\prod_{l=1}^{L}\left\{\Phi_{2}\left(\frac{D_{l, i}-\tilde{\pi}_{w}^{\prime}{ }_{w} \varpi_{w i}}{\sigma_{w}}, \tilde{\pi}_{e}^{\prime}{ }_{e} \varpi_{e i},-\rho_{e w}\right)-\Phi_{2}\left(\frac{D_{l-1, i}-\tilde{\pi}_{w}^{\prime} \varpi_{w i}}{\sigma_{w}}, \tilde{\pi}_{e}^{\prime}{ }_{e} \varpi_{e i},-\rho_{e w}\right)\right\}^{T_{i l}}\right]^{E_{i}},
\end{aligned}
$$

where $\rho_{e w}$ is the correlation between the error terms $v_{e}$ and $v_{w}$ in wife's employment and income equations respectively, $D_{l, i}=d_{l} / p_{i}$ represents the real income thresholds associated with each income category $l$ and observation $i, \Phi_{2}$ is the cumulative standard bivariate normal function, and

$$
T_{i l}=\left\{\begin{array}{l}
1 \text { if } I_{h i} \text { falls in the } l \text { th category } \\
0 \text { otherwise, } \\
\qquad(i=1,2, \ldots N, l=1,2, \ldots L)
\end{array}\right.
$$

\footnotetext{
${ }^{5}$ Husband's income is expected to have a negative effect on wife's hours of work due to the positive income effect of an increase in unearned income on wife's leisure (Killingsworth, 1983). Since wife's income is related to her hours of work, husband's income appears in equation (6).

${ }^{6} \mathrm{We}$ are not aware of any application of this variant of sample selection in econometric literature. The probit model with sample selection of van de ven Wynand and Bernard (1981) is a special case of this structure.
} 
The maximization of the logarithm of the likelihood function in equation (7) provides estimates of the wife's income equation. The employment equation (5) is estimated directly and as we will see, will be estimated again in conjunction with the car ownership equations. Consequently, there is a multiplicity of employment estimates. All these estimates are consistent and were found to be very close empirically. We use the univariate probit estimates of wife's employment parameter estimates for interpretation. Maximum likelihood estimation equation (7) is done to obtain consistent estimates of parameters for wife's income and, similarly, for car ownership.

Initial start values for the maximum likelihood iterations are obtained by a modification of the procedure adopted for husband's income estimation. We assign to each observation in the uncensored region, its conditional expectation based on the marginal distribution of the underlying latent continuous variable $I_{w i}{ }^{*}$. We now treat these values as the actual continuous income values and apply a Heckman's two step method for sample selection models to obtain start values for the parameters.

An imputed value of the wife's (log) income for employed wives is computed from the final MLE parameters as

$$
\begin{aligned}
\hat{I}_{w i}^{*} & =E\left(I_{w i}^{*} \mid E_{i}=l\right)=E\left(I_{w i}^{*} \mid E_{i}^{*}>0\right) \\
& =\hat{\pi}_{w}^{\prime} \omega_{w i}+\hat{\gamma}_{w} \hat{I}_{h i}+\hat{\rho}_{e w} \hat{\sigma}_{w} \hat{\lambda}_{i}
\end{aligned}
$$

where $\hat{\pi}_{w}, \hat{\gamma}_{w}, \hat{\rho}_{e w}$, and $\hat{\sigma}_{w}$ are estimated values obtained from the maximization of equation (7), and $\hat{\lambda}_{i}$ is an estimate of the familiar selectivity correction term (see Heckman, 1979). This imputed value serves as an unbiased estimate of income for employed wives and is used in the car ownership equation.

\subsection{Household Car Ownership}

The household car ownership choice is modeled as a two equation switching system with wife's employment behaving as the endogenous switch. We postulate a latent variable representing household motivation or intention to own cars in each switching regime. The observable information is the categorical car ownership variable. Assuming a normal distribution for the latent car ownership intention, an ordered response probit correspondence is established in each switching car ownership regime. The resulting two-equation switching car ownership system is as follows: 


$$
\begin{aligned}
C_{i}^{*} & =\pi_{c 1}^{\prime} \omega_{c i}+\gamma_{c 1}\left(\hat{I}_{h i}^{*}+\hat{I}_{w i}^{*}\right)+v_{c i} \text { if } E_{i}^{*}>0 \\
& =\pi_{c 0}^{\prime} \omega_{c i}+\gamma_{c 0} \hat{I}_{h i}^{*}+v_{c i} \quad \text { if } E_{i}^{*} \leq 0 \\
C_{i} & =k, \text { if } \psi_{k-1}<C_{i}^{*} \leq \psi_{k}, k=0,1, \ldots K, \psi_{-1}=-\infty, \psi_{K}=+\infty, \psi_{0}=0,
\end{aligned}
$$

where $v_{c}$ is a random error term associated with the car ownership equations. The $\psi$ 's are thresholds that determine the correspondence between the observed car ownership choice and the latent propensity to own cars. These are estimated along with the other parameters. Wife's (log) income and the husband's (log) income have identical coefficients in the "wife-employed" regime. Wife's $(\log )$ income does not appear in the second equation. Statistical tests for the equality of the income effect $\left(\gamma_{c 1}\right.$ and $\left.\gamma_{c 0}\right)$ and elements of the coefficient vectors $\pi_{c 1}$ and $\pi_{c 0}$ can be performed during estimation.

We treat the car ownership equations as a switching ordered probit system with wife's employment behaving as the endogenous switch. ${ }^{7}$ This switching system accommodates for possible correlation in unmeasured tastes that affect car ownership and wife's work choice. Defining

$$
\begin{aligned}
& \tilde{\pi}_{c 1}=\left(\pi_{c 1}^{\prime}, \gamma_{c 1}, \gamma_{c 1}\right)^{\prime} \\
& \widetilde{\omega}_{c i}=\left(\omega_{c i}^{\prime}, \hat{I}_{h i}^{*}, \hat{I}_{w i}^{*}\right)^{\prime} \\
& \tilde{\pi}_{c 0}=\left(\pi_{c 0}^{\prime}, \gamma_{c 0}\right)^{\prime} \\
& \bar{\omega}_{c i}=\left(\omega_{c i}^{\prime}, \hat{I}_{h i}^{*}\right)^{\prime},
\end{aligned}
$$

the appropriate likelihood function for estimation of the parameters in the switching ordered probit system is:

$$
\begin{aligned}
L_{c} & =\prod_{i=1}^{N}\left\{\left[\prod_{k=1}^{K}\left\{\Phi_{2}\left(\psi_{k}-\tilde{\pi}_{c 1}^{\prime} \widetilde{\omega}_{c i}, \tilde{\pi}_{e}^{\prime} \widetilde{\omega}_{e i},-\rho_{e c}\right)-\Phi_{2}\left(\psi_{k-1}-\tilde{\pi}_{c 1}^{\prime} \widetilde{\omega}_{c i}, \tilde{\pi}_{e}^{\prime} \widetilde{\omega}_{e i},-\rho_{e c}\right)\right\}^{W_{i k}}\right]^{E_{i}}\right. \\
& \left.\times\left[\prod_{k=1}^{K}\left\{\Phi_{2}\left(\psi_{k}-\widetilde{\pi}_{c 0}^{\prime} \bar{\omega}_{c i},-\tilde{\pi}_{e}^{\prime} \widetilde{\omega}_{e i}, \rho_{e c}\right)-\Phi_{2}\left(\psi_{k-1}-\tilde{\pi}_{c 0}^{\prime} \bar{\omega}_{c i},-\widetilde{\pi}_{e}^{\prime} \widetilde{\omega}_{2 i}, \rho_{e c}\right)\right\}^{W_{i k}}\right]^{l-E_{i}}\right\},
\end{aligned}
$$

where $\Phi_{2}$ is the cumulative normal bivariate distribution function, $\rho_{e c}$ is the correlation between $v_{e}$ and $v_{c}$, and

\footnotetext{
${ }^{7}$ We are not aware of any prior application of the endogenous switching ordered probit system in econometric literature. All applications of endogenous switching systems have been, to our knowledge, restricted to regression equations.
} 


$$
W_{i k}=\left\{\begin{array}{l}
1 \text { if the } i \text { th observation belongs to the } k \text { th car category } \\
0 \text { otherwise }
\end{array}\right.
$$

Initial start values for maximum likelihood iterations are obtained by applying a simple ordered probit procedure to each car ownership regime. While these estimates are subject to problems of selection bias, they will provide reasonable start values. The initial value for the correlation term $\rho_{e c}$ is set to zero.

\section{Empirical Specification and Results}

The choice of variables and the specification adopted in the model was guided by conceptual arguments, empirical evidence provided by earlier labor economic and car ownership studies and considerations of parsimony in representation. Table 1 provides a list of exogenous variables used in the model and their definitions. The variable termed "work acceptability" is the ratio of total female labor force (that is, all females who are employed, or, not employed but seeking jobs) to total active female population in each municipality. ${ }^{8}$ It represents the degree to which wife's working is considered acceptable or appropriate in each community. ${ }^{9}$

Price levels are assumed constant across regions in this analysis. The Netherlands is a small country and it may not be unreasonable to assume constant price levels in such a compact geographic area (Killingsworth, 1983). Thus, variations in the price index arise in this study from time series or wave differences in price level.

The estimation results for each equation are presented and discussed in the following sections.

\subsection{Husband's Income Equation}

The unit of measure used for the husband's income is real annual income in guilders per year. Three sets of variables are considered in the husband's income equation. These relate to the husband's age, husband's education and wave dummy variables. The results of the grouped data MLE estimation of husband's income (in log form) are shown in Table 2a.

\footnotetext{
${ }^{8}$ The data used in the computation of this index was obtained from the Central Bureau of Statistics (CBS), Netherlands.

${ }^{9}$ We recognize alternative interpretations of the work acceptability index which may represent a combination of location attributes. Viewed from this perspective, the index may be considered as a parsimonious representation for the set of local factors influencing wife's work participation.
} 
Age has a positive impact on husband's income presumably because it is a proxy for experience (Hausman and Wise 1976;1977); however, there is a decline in the magnitude of the age effect beyond 35 from +0.025 to +0.010 possibly attributable to decreasing returns to scale of experience and/or deterioration in efficiency and productivity (Mincer 1974). The effect of age beyond 45 is more complicated. For individuals with a low education, (log) income decreases beyond the age of 45 at a rate of $-0.011(=0.025-0.015-0.021)$. However, for individuals with medium to high education, the net effect is near zero $(-0.011+0.009)$. These results indicate a differential effect of age on productivity based on education level.

We introduce two dummy variables corresponding to secondary and high education levels (using primary education as the base category) to represent the effect of education on incomeearnings. Table 2a shows that there is a strong positive influence of the education dummy variables on husband's income, with high education having a greater influence than secondary education.

The wave dummy variables capture temporal variations in (real) income earning potential. Such temporal variations may arise from differences in the state of the economy, e.g., changes in costs of living and/or absolute income earnings.

Examination of the marginal effects of exogenous variables on husband's income (computed for mean variables values) provide additional insights into the estimation results and are presented in Table 2.

\subsection{Wife's Employment Equation}

The exogenous variable vector in the wife's work participation equation includes a dummy variable for husband's high education, wife's age and education variables, variables pertaining to the number and age distribution of children in the household, a work acceptability indicator, and wave dummy variables. In addition, wife's employment is influenced by husband's income.

The wife's employment equation is estimated using a probit model. Estimation results for the participation index $E^{*}$ are given in Table 3a. Husband's income decreases wife's work propensity in keeping with our presumption that leisure is a normal good (Killingsworth, 1983). Husband's education increases his wife's propensity to work. Geerken and Gove (1983) find a similar positive effect of husband's education on wife's employment propensity. Husband's education may be viewed as a measure of his ideological outlook on traditional gender roles. High education of the husband would then lead to a more egalitarian allocation of household responsibilities and, 
consequently, a relaxation of household constraints that affect wife's employment decision. It may also be associated with greater respect of the talents and ideals of the wife, thus decreasing the impact of any traditional inhibiting factors that influence wife's market work choice.

Wife's age increases her work propensity till age 40 . Beyond 40 , there is a decline in the employment participation index.

Wife's education increases the "monetary value" of her services (that is, her wages) in the market and is likely to intensify her employment inclination. Two dummy variables corresponding to secondary education and high education are defined for wife's education as was done for husband's education. Wife's high education has a positive effect on her work propensity, though secondary education does not have a significantly different effect from primary education.

Children increase the value of a wife's time at home and are potential sources of child care costs and other psychic costs of work outside the home (Nakamura and Nakamura 1983). Children's presence in the household is represented by the total number of children at home and the number of young children (under the age of 12). Our results indicate that children decrease the probability of a wife being employed, with the effect being larger for younger children.

As we would expect, the regional social acceptability of wife's work role (work acceptability) has a positive impact on wife's employment decision. The sign and magnitude of the wave dummy variables indicate increases in work intensity in later waves, suggesting a positive period effect.

The marginal effect of each variable on wife's work participation probability (computed for mean variable values) can be obtained from the estimation results and are presented in Table $3 \mathrm{~b}$.

\subsection{Wife's Income Equation}

The exogenous variables in the wife's income equation include the wife's age and education variables, work acceptability index, variables associated with the number and age distribution of children and wave dummy variables.

Estimates of the wife's income equation (in logarithmic form) after accounting for sample selection are presented in Table $4 \mathrm{a}$. The signs on all variables conform to our general expectations. Unobserved factors that affect wife's employment propensity and income earning potential are

significant and positively correlated as indicated by the estimate of $\rho_{e w}$. Marginal effects of the variables are provided in Table $4 \mathrm{~b}$. 


\subsection{Household Car Ownership Equation}

Exogenous variables employed in the specification of the car ownership equation include the husband's and wife's high education dummy variables, variables related to the number and age distribution of children, a dummy variable representing large cities, and the wave dummy variables.

Car ownership is modeled as a switching ordered probit system. We have two equations for car ownership -- one for "wife-employed" households and the other for "wife-unemployed" households. Each equation is defined for the entire population, not just for households in which the wife is employed or unemployed (Mare and Winship, 1988). The switching model accounts for unmeasured factors influencing wife's employment propensity and household car ownership intensity.

Tests of hypotheses concerning the equality of parameters between the two switching regimes resulted in rejection of the equality for all variables except "total number of kids" and "large city". The wave variables and "number of kids $<12$ " variable were found to be insignificant in both regimes. Estimation results for the resulting specification are shown in Table 5. The large negative values on the constant terms should be considered in conjunction with the coefficients on the $(\log )$ income variables since the constants account (in part) for the range in which the (log) income values occur.

The parameters on the $(\log )$ income variables in the two regimes indicate that the car ownership propensity is less sensitive to the husband's income in the "wife-employed" regime than in the "wife-unemployed" regime. It will be noted that the coefficient on the husband's and wife's (log) income variables in the "wife-employed" regime are identical by specification.

Households with high educated husbands tend to have fewer cars. This education effect is the impact of education after controlling for its influence through income. There is a significant (but smaller) effect of wife's education on household car ownership if she is employed. Wife's education is insignificant if she is unemployed.

Children reduce the car ownership propensity of a household. This effect reflects a combination of the negative effect of children (on car ownership) through increased expenditure on essential goods (Lerman and Ben-Akiva 1975) and the positive impact of children due to higher mobility requirements (Jones, et al., 1983; Barjonet, et al., 1989). The sign on this variable in our model suggests that the negative "increased expenditure" effect is larger than the positive mobility 
effect (Golob 1989, finds a comparable result in his dynamic model of household travel expenditures and car ownership). Finally, households in large metropolitan areas tend to have fewer cars, presumably due to the higher transit level of service and lower auto level of service (due to congestion problems, parking problems, etc.) associated with large cities.

The parameter $\psi_{1}$ represents the threshold car ownership intensity between one and two cars. The threshold between zero and one car is, by assumption, zero. The correlation between unmeasured factors influencing wife's employment propensity and likelihood of car ownership in the household, $\rho_{e c}$, is large and highly significant in our model. This indicates that unobserved factors that increase the propensity of a wife to work (wife's ability, lifestyle tastes, productivity, gender-role views of wife and husband, etc.) also increase the inclination to own cars. That is, the segmentation of the population by wife's employment is nonrandom with respect to the household's propensity to own cars.

The two equations of car ownership may be used to obtain the unconditional expectation of car ownership propensity, useful for car ownership forecasting, using the D-method of Goldfeld and Quandt (Goldfeld and Quandt, 1973; Lee, et al., 1979). This method obtains a single equation which gives the value of (unconditional) car ownership propensity and may be used to predict the

probability of car ownership and obtain marginal effects of exogenous variables on car ownership probability (Bhat and Koppelman 1991).

\section{Conclusion}

This paper develops an empirical model of employment, income, and car ownership. Employment and income are important determinants of travel and activity behavior. However, previous research has treated these variables as exogenous to travel analysis. This paper develops and implements a structure that incorporates employment and income into the travel analysis model system. Such a structure explicitly recognizes the behavioral linkages among employment, income and travel and their response to exogenous variables that represent the lifecycle and lifestyle of the individual and household.

The model developed in this paper is not only important for travel demand forecasting, it is also important in estimation. Traditional demand models, in general, handle grouped income data by using midpoints of class intervals. Such a method will, in general, not result in consistent parameters at the estimation stage. Taking explicit account of the grouped nature of income, as done here, 
eliminates the need to adopt inconsistent estimation procedures. The model also overcomes the inconsistency in parameter estimation of traditional travel demand models originating from correlation in unobserved factors affecting the employment decision and travel-related choices.

It is clear that there is considerable advantage and need to modeling employment and income within a transportation framework. While the estimation methodology is complicated, it provides a significant improvement in travel demand model estimation and, ultimately, forecasting.

The model developed here may be extended and refined in a number of ways. This study confines the sample used in empirical analysis to nuclear family households. It will be useful to apply the same model to different household types and interpret the similarity/dissimilarity in empirical results. An extension to other household types is also important from a forecasting viewpoint, since a model for each of the different household type segments is needed.

The equation system can be expanded to include an equation for trip generation. Other extensions can include broadening the scope of the current disaggregate model to incorporate other long-term household and individual decisions, such as residential location choice, occupational choice and employment location choice. An improved understanding of such long-term household decisions can facilitate the development of behaviorally sound models for travel demand forecasting. The present model is an important step in this direction. 


\section{REFERENCES}

Aitchison, J. and Brown J.A.C. (1976) The Lognormal Distribution with Special Reference to Its Uses in Economics. Cambridge University Press, Cambridge, MA.

Barjonet, P.E., Hivert L., Lefol J., Orfeuil J., and Troulay P. (1989) The automobile: Uses and users. In Travel Behavior Research, pp. 174-185. Gower Publishing Company, Aldershot, England.

Beggan J. G. (1988) The relationship between travel/activity behavior and mode choice for the work trip, unpublished. Masters Thesis, Transportation Center, Northwestern University, Evanston, IL.

Bhat, C.R. and Koppelman F.S. (1991) An endogenous switching simultaneous equation system of employment, income and car ownership. Research Report NU-TC-TB-91-2, Transportation Center, Northwestern University, Evanston, Illinois.

Cogan, J. (1980) Labor supply with costs of labor market entry. In Female Labor Supply: Theory and Estimation, pp. 25-89, Princeton University Press, Princeton, NJ.

Gaudry M. (1979) Six notions of equilibrium and their implications for travel modeling examined in an aggregate direct demand framework. In Behavioral Demand Modeling, pp. 137-163. Croom Helm, London.

Geerken and Grove (1983) At Home and at Work: The Family's Allocation of Labor. Sage Publications, Beverly Hills, CA.

Goldfeld, S.M. and Quandt R.E.(1973) The estimation of structural shifts by switching regressions. Annals of Economic and Social Measurement, 2, 475-485.

Golob T.F. (1989) The dynamics of household travel time expenditures and car ownership decisions. Presented at the International Conference on Dynamic Travel Behavior Analysis, Japan, Kyoto, July.

Greene W.H. (1983) Estimation of limited dependent variable models by ordinary least squares and the method of moments. Journal of Econometrics, 21, 195-212.

Hausman J.A. and Wise D.A. (1976) The evaluation of results from the truncated samples: The New Jersey income maintenance experiment. Annals of Economic and Social Measurement, 5/4, 421-445.

Hausman J.A. and Wise D.A.(1977) Social experimentation, truncated distributions, and efficient estimation. Econometrica, 45, 919-938.

Heckman J.J. (1979) Sample selection bias as a specification error. Econometrica, 47, 153-161. 
Hsiao C. (1983) Regression analysis with a categorized explanatory variable. In Studies in Econometrics, Time Series, and Multivariate Statistics, Academic Press, Inc., New York, pp. 93-129.

Jones P. M., Dix M. C., Clarke M. I. and Heggie I. G. (1983) Understanding Travel Behavior, Gower Publishing Company, Aldershot, England.

Killingsworth M.R. (1983) Labor Supply, Cambridge University Press, Cambridge, MA.

Lee L.F., Maddala G.S. and Trost R.P.(1979) Testing for structural change by D-methods in switching simultaneous equation models. In Proceedings of the American Statistical Association (Business and Economics Section), pp. 461-466.

Leibowitz, A. (1974) Home investments in children. Journal of Political Economy, Part II, MarchApril.

Lerman S.R. and Ben-Akiva M. (1975) Disaggregate behavioral model of automobile ownership. Transportation Research Record, 569, 34-51.

Mare R. D. and Winship C. (1987) Endogenous Switching Regression Models for the Causes and Effects of Discrete Variables. Center for Demography and Ecology, University of Wisconsin, Madison.

Meurs H. (1989) Dynamic analysis of trip generation, presented at the International Conference on Dynamic behavior analysis, Kyoto, Japan, July 21-23.

Mincer, J. (1974) Schooling, Experience and Earnings. National Bureau of Economic Research, New York.

Nakamura A. and Nakamura M.(1983) Part-time and full-time work behavior of married women: A model with a doubly truncated dependent variable. Canadian Journal of Economics, May, $229-257$.

Stern, S. (1991) Imputing a continuous income variable from a bracketed income variable with special attention to missing observations. Economic Letters, 37, pp. 287-291.

van de ven Wynand P. M. M and van praag Bernard M.S. (1981) The demand for deductibles in private health insurance: A probit model with sample selection. Journal of Econometrics, 17, $229-252$. 
Table 1. List of Exogenous Variables in Model

\begin{tabular}{|c|c|}
\hline Variable & Definition \\
\hline Husband's age & Age of husband \\
\hline Husband's age $>35$ & $\begin{array}{l}\text { (Husband's age-35) if husband's age greater than } 35 \text {, } \\
0 \text { otherwise }\end{array}$ \\
\hline Husband's age $>45$ & $\begin{array}{l}\text { (Husband's age-45) if husband's age greater than } 45 \text {, } \\
0 \text { otherwise }\end{array}$ \\
\hline Husband's secondary education & $\begin{array}{l}1 \text { if husband's education is at secondary level, } \\
0 \text { otherwise }\end{array}$ \\
\hline Husband's high education & $\begin{array}{l}1 \text { if husband's education is high, } \\
0 \text { otherwise }\end{array}$ \\
\hline $\begin{array}{l}\text { Husband's age }>45 \text { and sec/high } \\
\text { education }\end{array}$ & $\begin{array}{l}\text { (Husband's age-45) if husband's age greater than } 45 \\
\text { and husband's education is secondary or high, } \\
0 \text { otherwise }\end{array}$ \\
\hline Wave 1 & $\begin{array}{l}1 \text { if household is in wave } 1 \\
0 \text { otherwise }\end{array}$ \\
\hline Wave 3 & $\begin{array}{l}1 \text { if household is in wave } 3, \\
0 \text { otherwise }\end{array}$ \\
\hline Wave 5 & $\begin{array}{l}1 \text { if household is in wave } 5 \text {, } \\
0 \text { otherwise }\end{array}$ \\
\hline Wave 7 & $\begin{array}{l}1 \text { if household is in wave } 7, \\
0 \text { otherwise }\end{array}$ \\
\hline Wave 9 & $\begin{array}{l}1 \text { if household is in wave } 9 \text {, } \\
0 \text { otherwise }\end{array}$ \\
\hline Wife's age & Wife's age \\
\hline Wife's age $>40$ & $\begin{array}{l}\text { (Wife's age-40) if wife's age greater than } 40 \text {, } \\
0 \text { otherwise }\end{array}$ \\
\hline Wife's secondary education & $\begin{array}{l}1 \text { if wife's education is at secondary level, } \\
0 \text { otherwise }\end{array}$ \\
\hline Wife's high education & $\begin{array}{l}1 \text { if wife's education is high, } \\
0 \text { otherwise }\end{array}$ \\
\hline Work acceptability* & Regional social acceptability of wife's work role \\
\hline Number of kids & Number of children less than 12 in household \\
\hline Total number of kids & Total number of children in household \\
\hline
\end{tabular}

* calculated as the ratio of female labor force to total female population between 15 yrs and 64 yrs for each region. 
Table 2a. (Log) Husband's Income Estimates

\begin{tabular}{|l|c|c|c|}
\hline \multicolumn{1}{|c|}{ Variable } & Coefficient & Standard error & Coef./Std.error \\
\hline \hline Constant & 9.131 & 0.098 & 93.05 \\
\hline Husband's age & & & \\
Entire range & 0.025 & 0.003 & 8.50 \\
> 35 years & -0.015 & 0.004 & -3.54 \\
> 45 years & -0.021 & 0.006 & -3.65 \\
Husband's age > 45 and sec/high & 0.009 & 0.002 & 4.31 \\
Education & & & \\
Husband's education & & & \\
Secondary & 0.203 & 0.012 & 16.75 \\
High & 0.385 & 0.013 & 28.76 \\
\hline Wave variables & & & \\
one & 0.057 & 0.016 & 3.64 \\
five & 0.012 & 0.015 & 0.84 \\
seven & 0.018 & 0.015 & 1.19 \\
nine & 0.021 & 0.015 & 1.38 \\
\hline \hline$\sigma_{h}$ & 0.207 & 0.005 & 42.45 \\
\hline
\end{tabular}

Table 2b. Marginal Effects on Real Value of Husband's Income (guilders)

\begin{tabular}{|l|c|}
\hline \multicolumn{1}{|c|}{ Variable } & Marginal Effect on Husband's Income \\
\hline \hline Husband's age (per year) & 702 \\
< 35 years & 288 \\
35 - 45 years & -294 \\
> 45 years - prim./sec. educ. & -46 \\
> 45 years - high education & \\
\hline Husband's education & 5,131 \\
Secondary & 10,858 \\
High & \\
\hline \hline
\end{tabular}


Table 3a. Wife's Employment Propensity Estimates

\begin{tabular}{|l|c|c|c|}
\hline \multicolumn{1}{|c|}{ Variable } & Coefficient & Standard error & Coef./Std.error \\
\hline \hline Constant & 1.744 & 3.102 & 0.56 \\
\hline Husband's (log) income & -0.644 & 0.324 & -2.00 \\
\hline Husband's high education & 0.251 & 0.114 & 2.19 \\
\hline Wife's age & & & \\
Entire range & 0.058 & 0.010 & 5.59 \\
$\quad>40$ years & -0.127 & 0.022 & -5.70 \\
\hline Wife's education & & & 1.15 \\
Secondary & 0.083 & 0.072 & 4.72 \\
High & 0.475 & 0.101 & -4.06 \\
\hline Children & & & -1.99 \\
Total number & -0.244 & 0.060 & 6.09 \\
No. $<12$ years & -0.099 & 0.050 & 1.53 \\
\hline Work acceptability & 4.853 & 0.796 & 3.60 \\
\hline Wave variables & & & \\
three/five & 0.132 & 0.086 & 0.085 \\
seven/nine & 0.307 & & \\
\hline \hline
\end{tabular}

Table 3b. Marginal Effects on Wife's Employment Probability

\begin{tabular}{|l|c|}
\hline \multicolumn{1}{|c|}{ Variable } & Marginal Effect \\
\hline \hline Husband's income (shift of 1000 guilders) & -0.007 \\
\hline Husband's high education & 0.077 \\
\hline Wife's age (per year) & 0.018 \\
$\quad<40$ years & -0.021 \\
$>$ >0 years & \\
\hline Wife's education & 0.025 \\
Secondary & 0.145 \\
High & \\
\hline Children (each child) & -0.075 \\
>12 years & -0.105 \\
$<12$ years & 0.015 \\
\hline Work acceptability index (shift of 0.01 ) & \\
\hline
\end{tabular}


Table 4a. (Log) Wife's Income Estimates

\begin{tabular}{|l|c|c|c|}
\hline \multicolumn{1}{|c|}{ Variable } & Coefficient & Standard error & Coef./Std.error \\
\hline Constant & 10.097 & 3.399 & 2.97 \\
\hline Husband's (log) income & -0.410 & 0.355 & -1.16 \\
\hline Husband's high education & 0.350 & 0.125 & 2.79 \\
\hline Wife's age & & & \\
$\quad$ Entire range & 0.016 & 0.012 & 1.28 \\
$\quad>40$ years & -0.034 & 0.025 & -1.34 \\
\hline Wife's education & & & \\
$\quad$ Secondary & 0.458 & 0.081 & 5.62 \\
High & 0.980 & 0.124 & 7.92 \\
\hline Children & & & \\
Total number & -0.116 & 0.074 & -1.56 \\
$\quad$ No. $<12$ years & -0.051 & 0.056 & -0.91 \\
\hline Work acceptability & 3.744 & 0.954 & 3.93 \\
\hline Wave variables & & & \\
three/five & 0.105 & 0.105 & 1.00 \\
seven/nine & 0.133 & 0.108 & 1.24 \\
\hline$\sigma_{\mathrm{w}}$ & 0.671 & 0.064 & 10.46 \\
\hline$\rho_{\mathrm{ew}}$ & 0.447 & 0.173 & 2.60 \\
\hline
\end{tabular}

Table 4b. Marginal Effects on Wife's Income

\begin{tabular}{|l|c|}
\hline \multicolumn{1}{|c|}{ Variable } & Marginal Effect on Wife's Income \\
\hline \hline Husband's income (shift of 1000 guilders) & -87 \\
\hline Husband's high education & 2100 \\
\hline Wife's age (per year) & 96 \\
$\quad<40$ years & -107 \\
$>40$ years & \\
\hline Wife's education & 2747 \\
Secondary & 5878 \\
High & -697 \\
\hline Children (each child) & -1005 \\
$>12$ years & 225 \\
$<12$ years & \\
\hline Work acceptability index (shift of 0.01$)$ & \\
\hline
\end{tabular}


Table 5. Car Ownership Propensity Estimates

\begin{tabular}{|c|c|c|c|}
\hline Variable & Coefficient & Standard Error & Coef./Std. Error \\
\hline \multicolumn{4}{|c|}{ "Wife-Employed" Household Regime } \\
\hline Constant & -18.365 & 3.841 & -4.78 \\
\hline Husband's (log) income & 1.002 & 0.201 & 4.99 \\
\hline Wife's (log) income & 1.002 & 0.201 & 4.99 \\
\hline Husband's high education & -0.565 & 0.157 & -3.60 \\
\hline Wife's high education & -0.388 & 0.196 & -1.98 \\
\hline \multicolumn{4}{|c|}{ "Wife-Unemployed" Household Regime } \\
\hline Constant & -15.039 & 2.139 & -7.03 \\
\hline Husband's (log) income & 1.626 & 0.212 & 7.66 \\
\hline Husband's high education & -0.258 & 0.110 & -2.52 \\
\hline Wife's high education & 0.040 & 0.093 & 0.43 \\
\hline \multicolumn{4}{|c|}{ Common Parameters in the Two Regimes } \\
\hline Total number of kids & -0.082 & 0.038 & -2.18 \\
\hline Large city & -0.332 & 0.073 & 4.54 \\
\hline$\rho_{\mathrm{ec}}$ & 0.509 & 0.088 & 5.77 \\
\hline$\Psi_{1}$ & 2.416 & 0.078 & 31.16 \\
\hline
\end{tabular}

